\title{
REVIEW OF THE
}

URBAN HEALTH AND

\section{WELLBEING} PROGRAMME
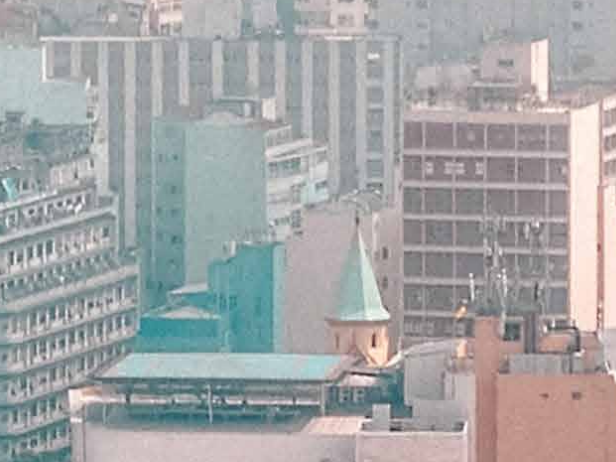

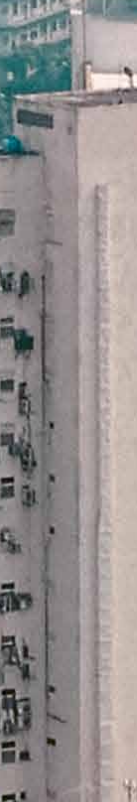

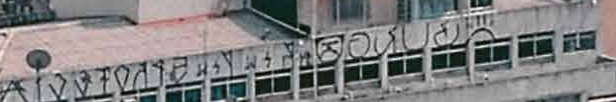
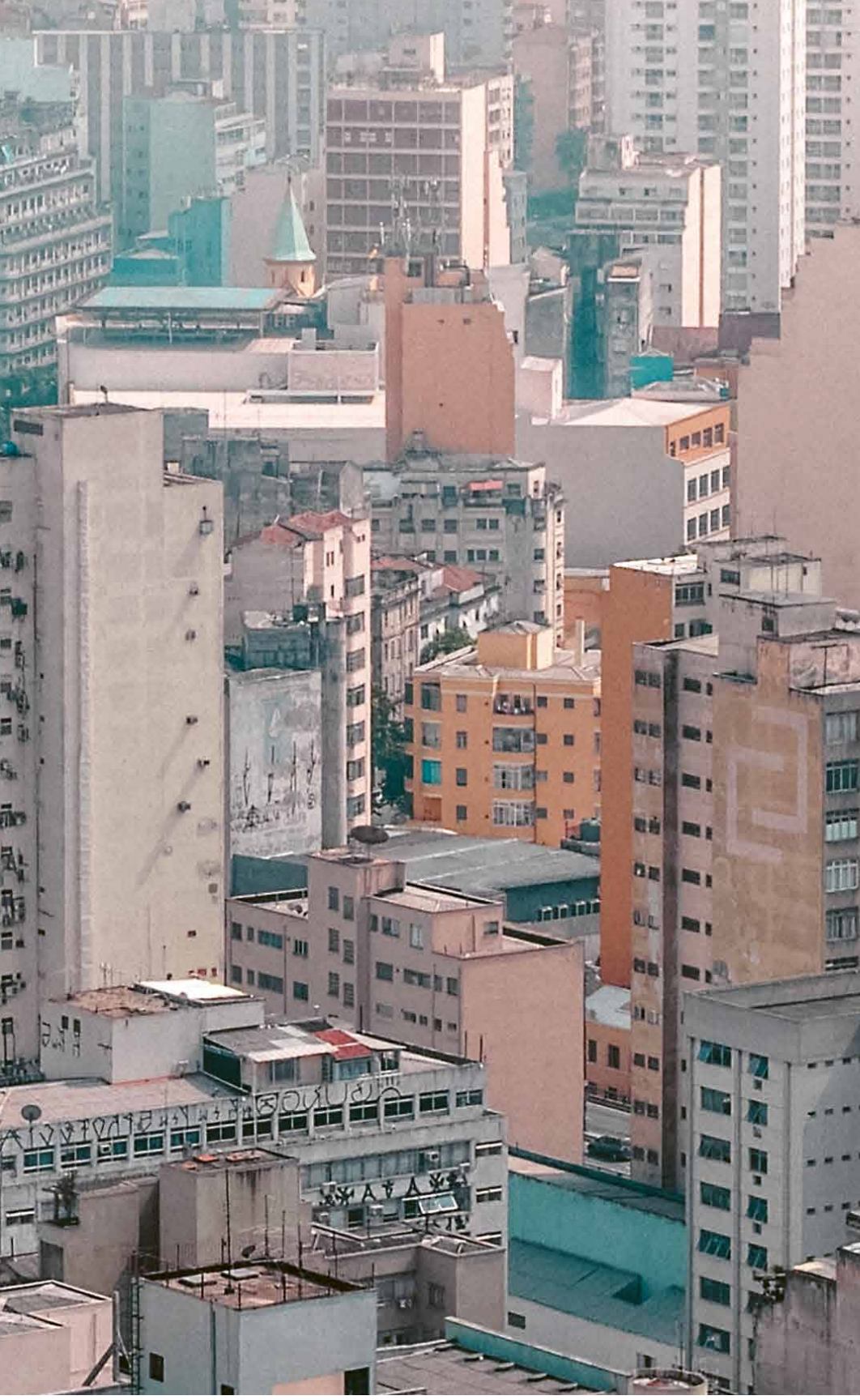

coselinima

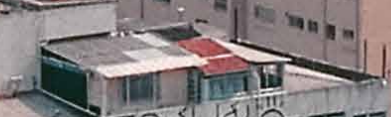

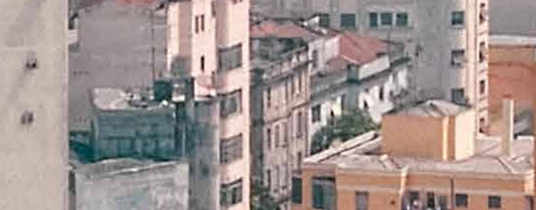
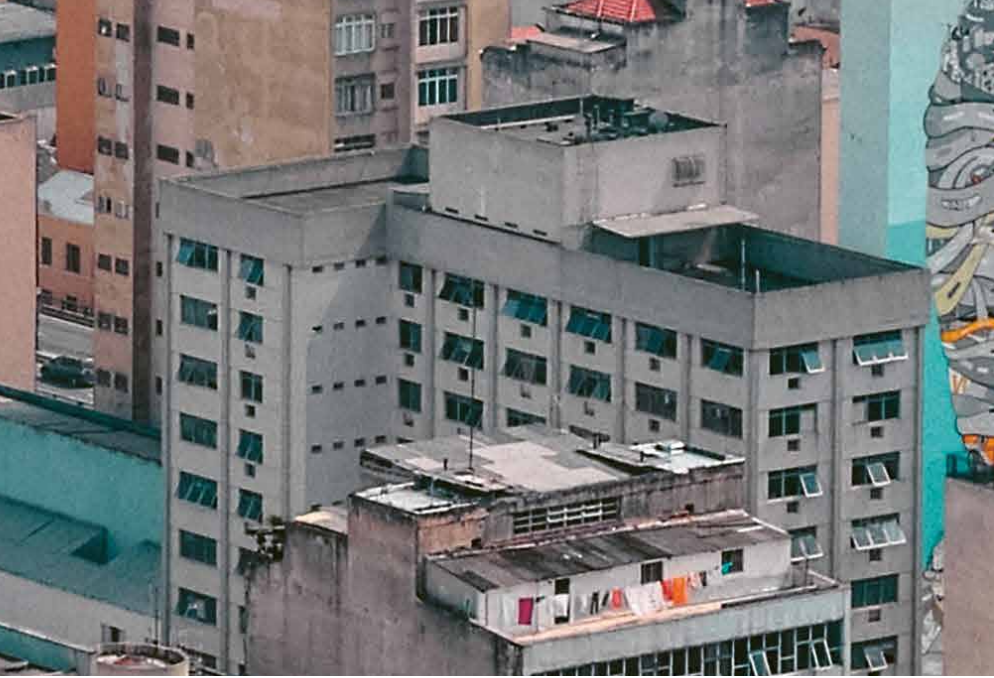

a्din
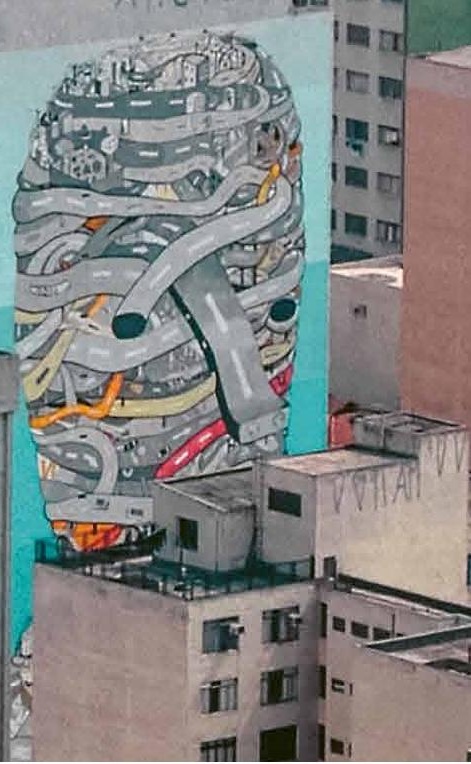

(2)

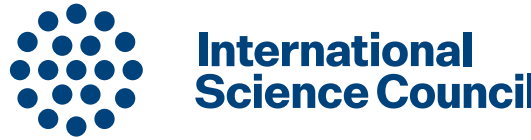





\section{REVIEW OF THE \\ URBAN HEALTH AND WELLBEING PROGRAMME}




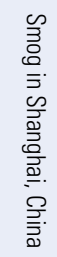

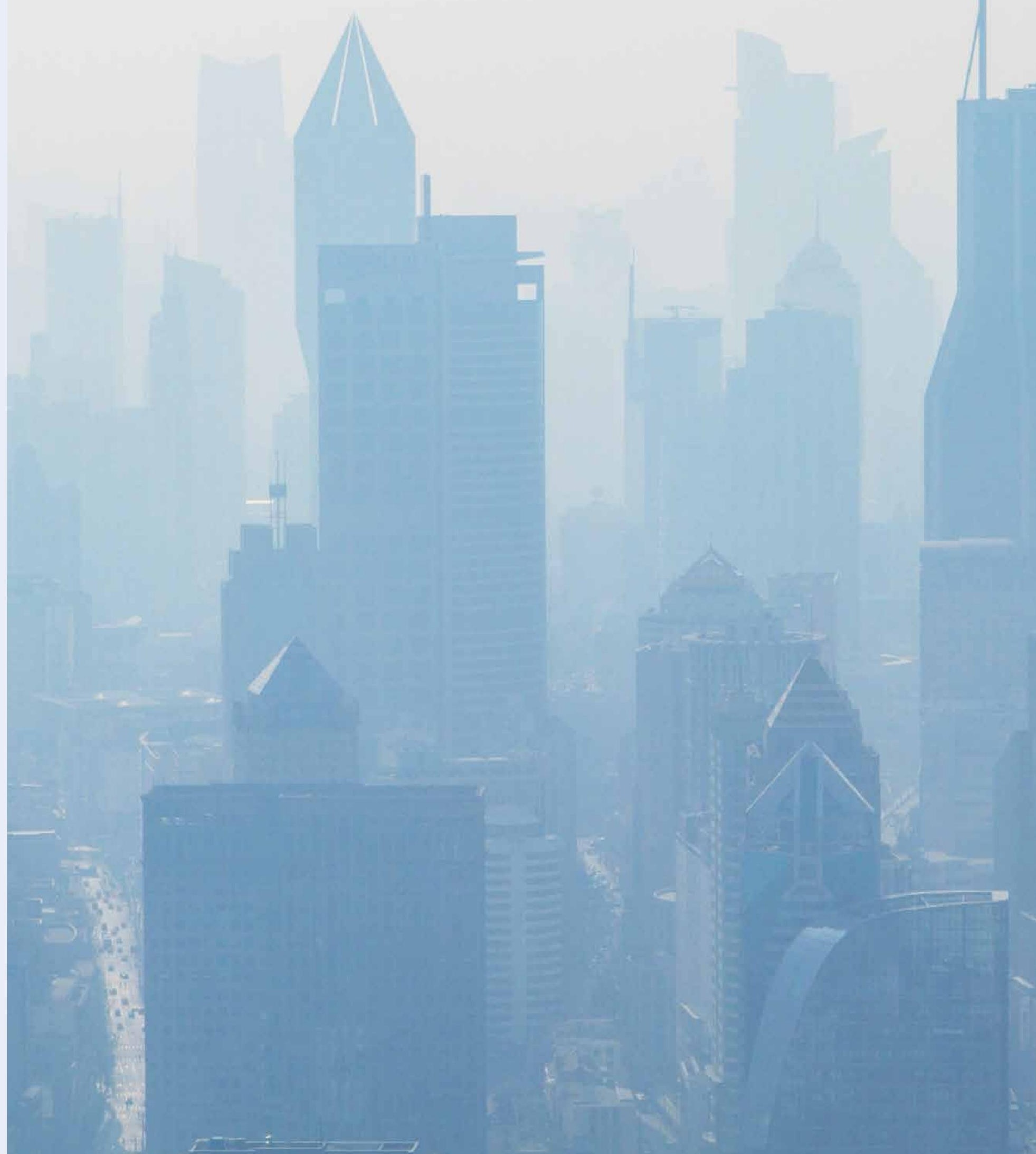




\section{EXECUTIVE SUMMARY}

This report documents the independent mid-term formative review of the International Science Council (ISC) ${ }^{1}$ programme of work entitled "Urban Health and Wellbeing: A Systems Approach". This programme, established in 2014, is currently co-sponsored by the United Nations University International Institute of Global Health (UNU-IIGH) and the InterAcademy Partnership (IAP), with significant financial support from the Chinese Academy of Sciences (CAS) in Xiamen, China.

As the review is intended to inform the next phase of this ten-year programme, the review panel purposefully focused its work on identifying critical areas for growth and direction.

\section{KEY FINDINGS}

- The review panel's overall assessment is that the International Programme Office (IPO) has developed an ambitious 'science plan' and an impressive steering committee, as well as local hosts.

- In the first three or so years, the IPo has experienced several challenges in meeting its goals and objectives as set out in the plan. These challenges, expected with any new IPO, range from issues related to language and staffing to clarity of expectations. The review panel is of the opinion that the core idea for the programme to produce policy-relevant research - was ambitious, and that given limited resources, it requires careful re-thinking on how to go forward. The plan for the coordination of research projects has not been realized.

\section{RECOMMEN DATIONS}

In the considered opinion of the review panel, the programme is not on course to achieve the objectives as stated in the original science plan. As logical next steps, the review panel recommends that:

- The leadership of the IPO should work in partnership with the CAS and the steering committee to revise the science plan in order to render goals and objectives relevant, feasible and attainable.

- The IPO is strongly encouraged to establish a logic model and/or metrics of measurement (e.g. key performance indicators) that would serve both as a rudder for day-to-day operations and as a framework for evaluation.

The review panel also strongly believes that the programme possesses sufficient strength to enable scaled-down, targeted impact in its next and final phase, once appropriate staffing measures have been implemented. 


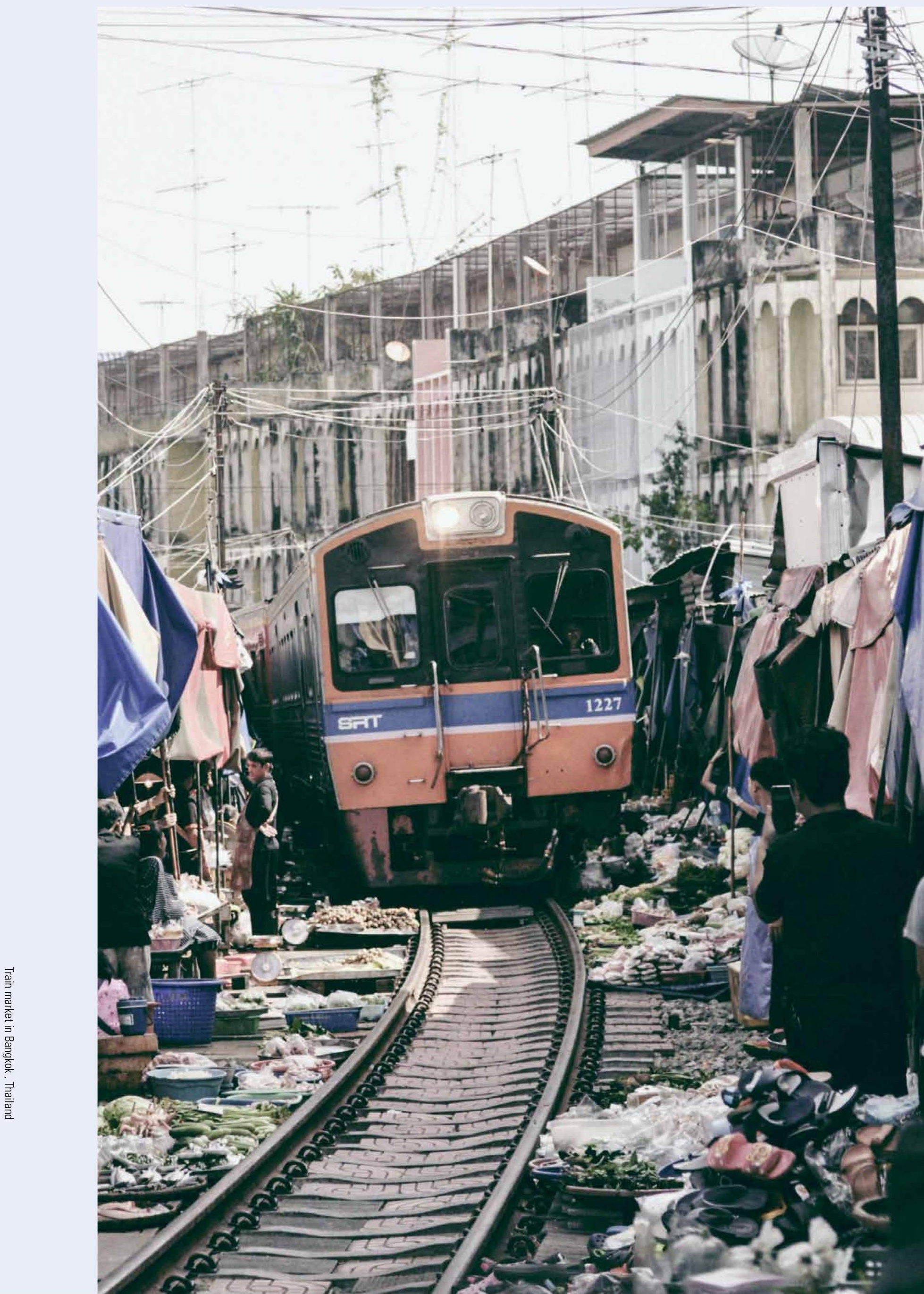




\section{INTRODUCTION}

Human health was identified in the International Council for Science (ICSU) Strategic Plan (2006-2011) as a new research priority, with the stated goal "to ensure that health considerations are duly taken into account in the planning and execution of future activities by building on the relevant strengths of Scientific Unions and Interdisciplinary Bodies.”

To more clearly define how ICsu might contribute to science for human health, a scoping group was established in 2006. The role of the scoping group was to consider the health initiatives already being developed within the ICSU community and identify additional areas or approaches where ICSU might add value to these initiatives.

The scoping group identified that a number of ICsu's Scientific Unions and Interdisciplinary Bodies had begun developing an initiative on science for health and well-being from as early as 2002. And in 2007, the Earth Systems Science Partnership, which brought together ICsU's global environmental change programmes, published a science plan for global environmental change and human health. At the same time, the ICSU Regional Office for Africa had carried out an analysis of health research needs for the continent. These initiatives reflect an increasing awareness and interest, in both the policy and research realms, of links between modern urban human ecology and the risks of a range of adverse health outcomes.

After consultation with the ICsU scientific community, a new planning group was established in 2008 to carry forward ideas identified in the scoping exercise. The result was the present science plan that proposes an innovative conceptual framework for considering the multi-factorial nature of both the determinants and the manifestations of health and well-being in global urban populations. In addition to stimulating specific research projects, a new science programme for urban health and well-being (UHWB) was mandated to focus on:
- Developing new methodologies and identifying data needs and knowledge gaps.

- Building and strengthening scientific capacity.

- Facilitating communication and outreach.

In so doing, the activities of the Uнwв programme are meant to:

- Promote a systems approach to human health and well-being in a changing urban environment among scientists and decision-makers.

- Strengthen capacity to conduct research on human health and well-being in a changing urban environment using a systems approach.

- $\quad$ Advocate for funding systems approaches for human health and well-being in changing urban environments.

- $\quad$ Enhance understanding of urban health and well-being issues across disciplines and sectors.

- Mediate science and technology alliances for implementing smart technology solutions for urban health and well-being.

- Influence the international agenda to encompass urban health initiatives.

In line with the 'standard' ICsu model for programme implementation, these activities were to be overseen and guided by a dedicated international, interdisciplinary Scientific Committee and an IPo established to ensure effective implementation. This was envisaged as a 10-year initiative, to allow sufficient time for the research and policy communities concerned with urban health and well-being to adopt systems analysis approaches.

In 2011, the General Assembly of ICSU endorsed plans for the new global initiative "Health and Wellbeing in the Changing Urban Environment: a Systems Analysis Approach”. In 2014, the IPo was opened in Xiamen, China, hosted by the Institute of Urban Environment (IUE) at the CAS, providing a hub for interdisciplinary scientific knowledge development, exchange and communication. 


\section{URBAN HEALTH AND WELL-BEING: THE PROGRAMME}

The Uнwв programme is a global science programme and interdisciplinary body of the International Science Council, supported by the UNUIIGH and the IAP. Its IPO is hosted by the IUE of the CAs in Xiamen, China.

The programme's vision is to generate policy-relevant knowledge based on a systems approach that will improve health status, reduce health inequalities and enhance the well-being of global urban populations. The programme is designed to build on, and create synergies with, science and policy communities, focusing on population health and addressing a critically important but as-yet inadequately studied perspective on the systemic determinants of human health and well-being.

The programme envisions future healthy cities functioning as integrated complex systems that sustainably provide benefits for the health and well-being of residents without compromising planetary health.

The goals of this science programme reflect a structure as proposed by the planning group report (ICSU 2011):
3 Building and strengthening capacity by building scientific capacity and supporting the interdisciplinary platforms necessary for undertaking research into urban health and well-being using a systems approach; by building the capacity of policy-makers and practitioners to understand scientific research on urban health and well-being using a systems approach; by facilitating the establishment of networks in research, business and civil society communities which take a systems approach to urban health and well-being; and by expanding the number of students and young scientists with an interest in undertaking research and entrepreneurial and civil engagement activities for urban health and well-being using systems approaches that engage with substantive policy-relevant issues.

4 Communicating new knowledge: promotion and outreach by creating a virtual forum as a point of reference for the scientific community and other stakeholders; by promoting interaction and collaboration between researchers and with other relevant stakeholders, via conferences and workshops; and by making results available to multiple stakeholders in a relevant format that allows them to be easily understood.

\section{Promoting and coordinating research} projects by generating high-impact scholarly outputs; by enabling better-informed decision-making from the variety of stakeholders involved in urban health and well-being; and by establishing systems approaches to health and well-being in the urban environment as a thriving and relevant area of interdisciplinary research.

2 Developing methodologies and identifying data needs by proposing innovative systems methodologies and approaches that are applicable to the particular challenges of health and well-being in the urban environment; by identifying data needs that inform and influence the various ongoing and planned observation and monitoring initiatives; and by identifying new data from third research studies that can be made openly available.

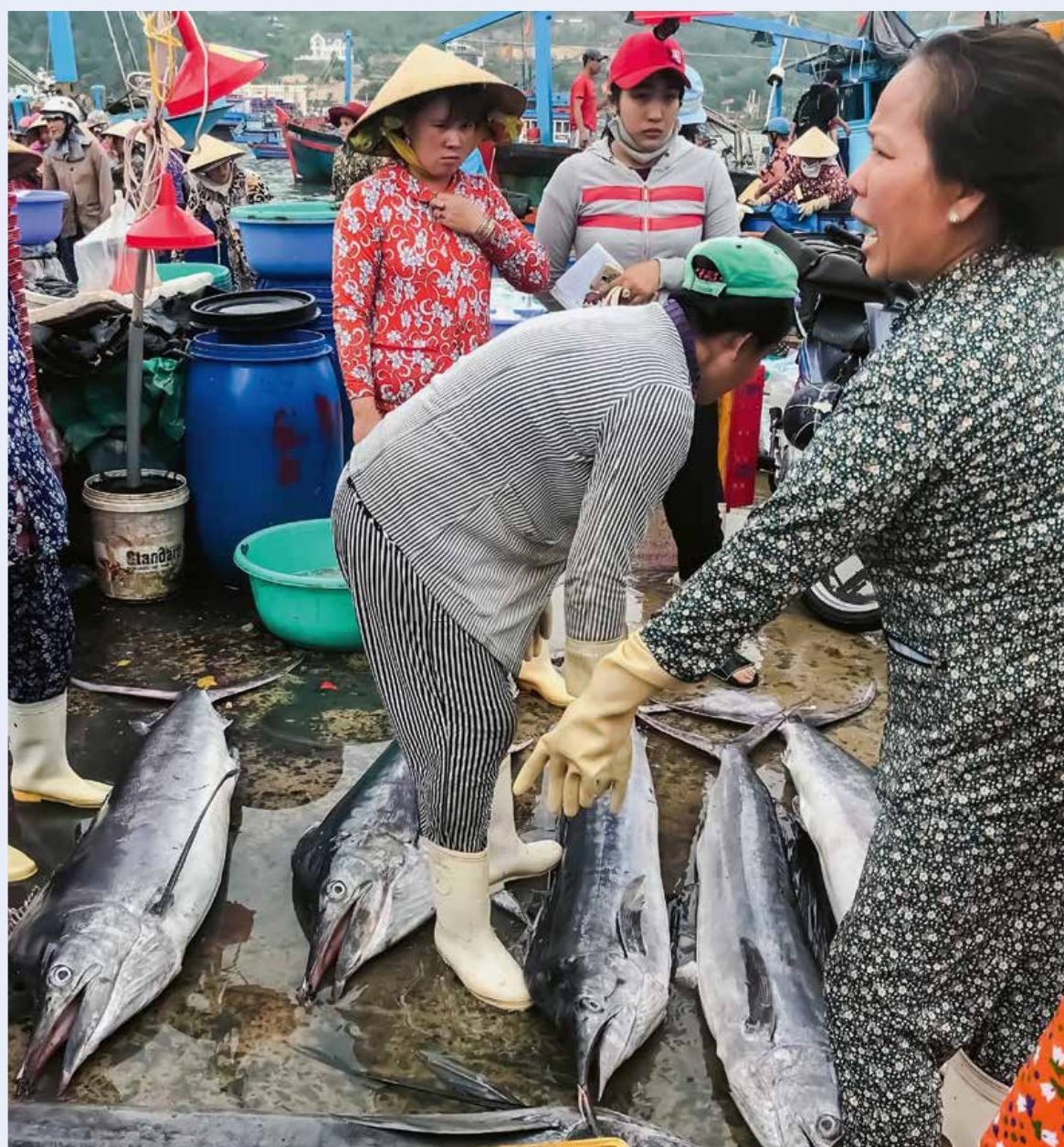




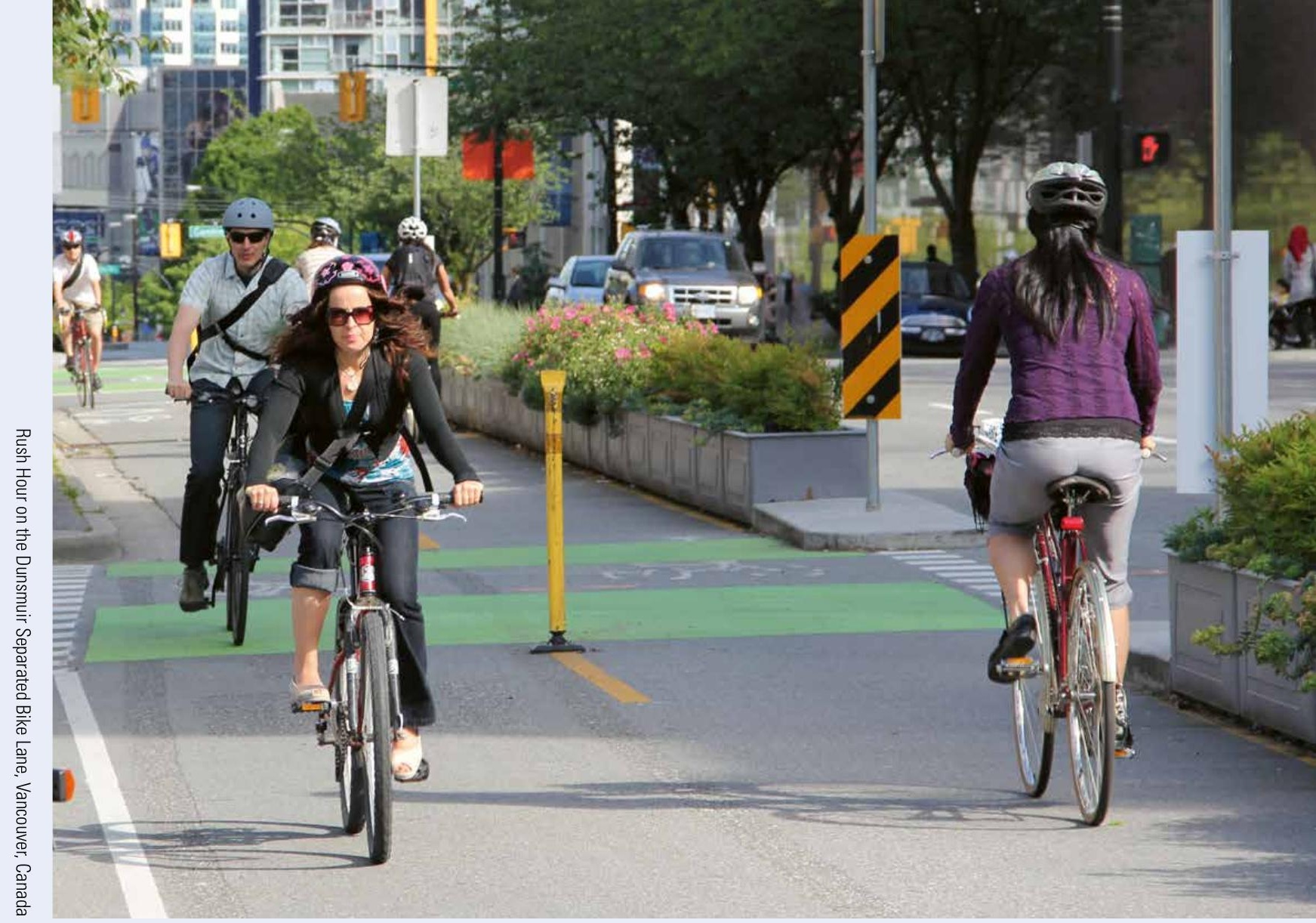

\section{THE NEW URBAN CONTEXT}

In the context of global environmental, economic and social change, perhaps no phenomenon is more striking than urbanization. Already, more than half of the world's population lives in urban places. Urban lifestyles and the increasing diversity of urban conditions have created not only new social hierarchies and cultural rules, but also a new set of roles for healthcare systems and changing patterns of access to and demand for health and other resources within and between cities. Urbanization represents both opportunity and risk, and a fresh set of challenges for those concerned with protecting and promoting human health and well-being. Propinquity gives rise to both benefits and disbenefits - economies of agglomeration and scale, but also diseconomies of congestion and institutional overload.

Cities have become central to securing the sustainable futures laid out in the New Urban Agenda, the Sustainable Development Goals and other landmark elements of the 2030 Agenda for Sustainable Development. The three pillars of economic, social, and environmental transitions can be best achieved within cities, which account for $75 \%$ of global GDP and $75 \%$ of global carbon emissions, and city-level actors play an increasingly important role in global and regional affairs.

Science also has a role to play in catalysing the sustainability transition and can be a powerful partner for political actors and decision-makers. The pathways in which science can influence policy and support change must be strengthened and fostered.

The urbanization megatrend (1.5 million people a week are added to the global urban population, and $90 \%$ of that growth takes place in African and Asian countries) will place huge demands on infrastructure, services, job creation, climate, the environment, and well-being. Longstanding knowledge-generating machineries such as the Intergovernmental Panel on Climate Change (IPCC) have taken on the urban challenge. But this global urban transition needs a multiscale and multi-dimensional approach. 


\section{REVIEW CRITERIA 1 STRATEGIC PLANNING AND IMPLEMENTATION}

Overall, the Uнwв programme is a long way from reaching its overarching goals. The reviewers suggest that what is needed in the short term is a system of prioritization of activities and a concomitant sense of where best to apply limited resources. Moreover, there needs to be more of a targeted approach to engagement - with partners, other researchers, policy-makers and civil society. The programme, through its Scientific Committee, should work to develop a more strategic and focused work plan.

The reviewers do recognize that the IPO has put considerable effort into writing research applications and attending scientific meetings in an effort to meet the goal of coordinating research projects. However, much of this effort has been opportunistic rather than strategic, and the Science Committee needs to provide stronger guidance on where to expend energy given that resources are limited.

The goal of developing methodologies for data needs remains to be met. Through engaging its Scientific Committee, the programme has built a strong foundation by establishing a loose 'network' of active system science researchers. The opportunity over the next five years is to expand and strengthen this network.

The programme has also struggled to achieve the goal of 'coordinating' research. This has proved challenging for a number of reasons: limited resources (staffing); language issues; the Executive Director's work description (i.e. only $20 \%$ of time should be dedicated to research activities); and the terms of reference of the Scientific Committee (i.e. not to generate the research outputs of the programme). With these constraints, it is difficult to see where original research will be produced.

The programme has worked to drive the promotion of the 'systems approach' - as exemplified by the various workshops and meetings in which the Executive Director has actively participated. However, due to limited resources, and the fact that the programme has not been able to recruit a Communications Officer, promotion of the programme's activities has not been as effective as anticipated. A more pragmatic approach is required going forward, that encourages the secretariat of the IPO to perform in a hybrid mode that generates external resources, while at the same time facilitates and promotes the research activities of others - that is, external partners.

The programme's positive engagement with the International Society for Urban Health (ISUH), and in particular its annual congress, provides an ideal opportunity to find a base through which to engage academics, and foster the development of a new generation of system scientists. Moreover, with the leadership of the eminent Scientific Committee, there is an opportunity to grow the field by publishing special journal issues as well as internationally published edited monographs related to issues at the forefront of systems science (for example, the IsuH's journal).

Strengthening, formalizing, promoting, supporting and utilizing system science researchers already in the network should be a key focus. A main goal should be to capitalize on these researchers' expertise to train the next generation of system scientists in the cutting-edge area of undertaking systems science. Creating a formal network of system scientists - particularly early

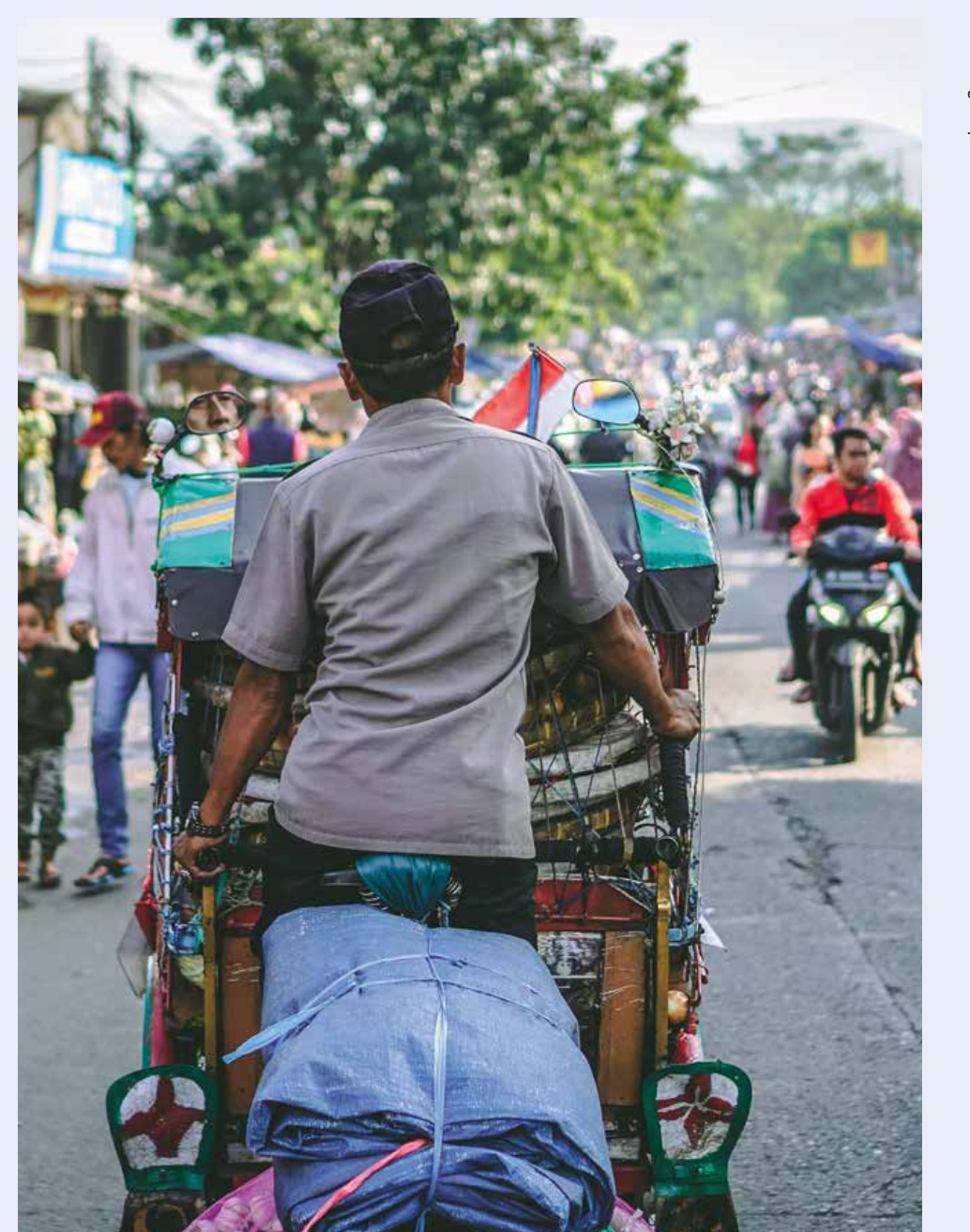


and mid-career academics that are able to foster individual research and publish new findings will help provide a more active portfolio for the programme.

Given the rapid urbanization occurring in China, and the fact that the programme is located there, it would be a missed opportunity if efforts were not made to develop a network of system scientists in the country. The host organization, the IUE, must and should play a key role in establishing, promoting and facilitating this network, with a domestic scientific committee overseeing its development.

\section{REVIEW CRITERIA 2 GOVERNANCE}

The UнwB programme consists of staff at the IPO (the Executive Director and Administrative Assistant at time of writing; there is no Science Officer or Communications Officer), and the Scientific Committee. The Scientific Committee defines the priorities and implementation strategy of the programme, elaborates policy and plays an advocacy role. This includes working with the Executive Director in soliciting the additional funds necessary for the conduct of programme activities directed by, or coordinated through, the IPO. The programme operates under the infrastructure of the host institution - the Institute of Urban Environment located at the Chinese Academy of Sciences - which provides internal services and financial support, operating under the institution's and host country's internal standard operating procedures.

In reality, the programme is too small to warrant an elaborate governance structure. However, at the same time, roles and responsibilities appear to be in conflict. A major challenge for the Executive Director is the competing priorities of the international programme vis-à-vis its location within a Chinese research centre; and restrictions on the amount of time allocated for research activities (i.e. 20\%). Efforts to overcome these tensions need to be resolved, with expectations clarified on what is achievable within the constraints of the role.

This clarification should be carried out in line with a strategic planning meeting facilitated by the Scientific Committee in order to focus the programme's mission, vision, and action plans during its final phase. The 2019 International Conference on Urban Health, which the programme

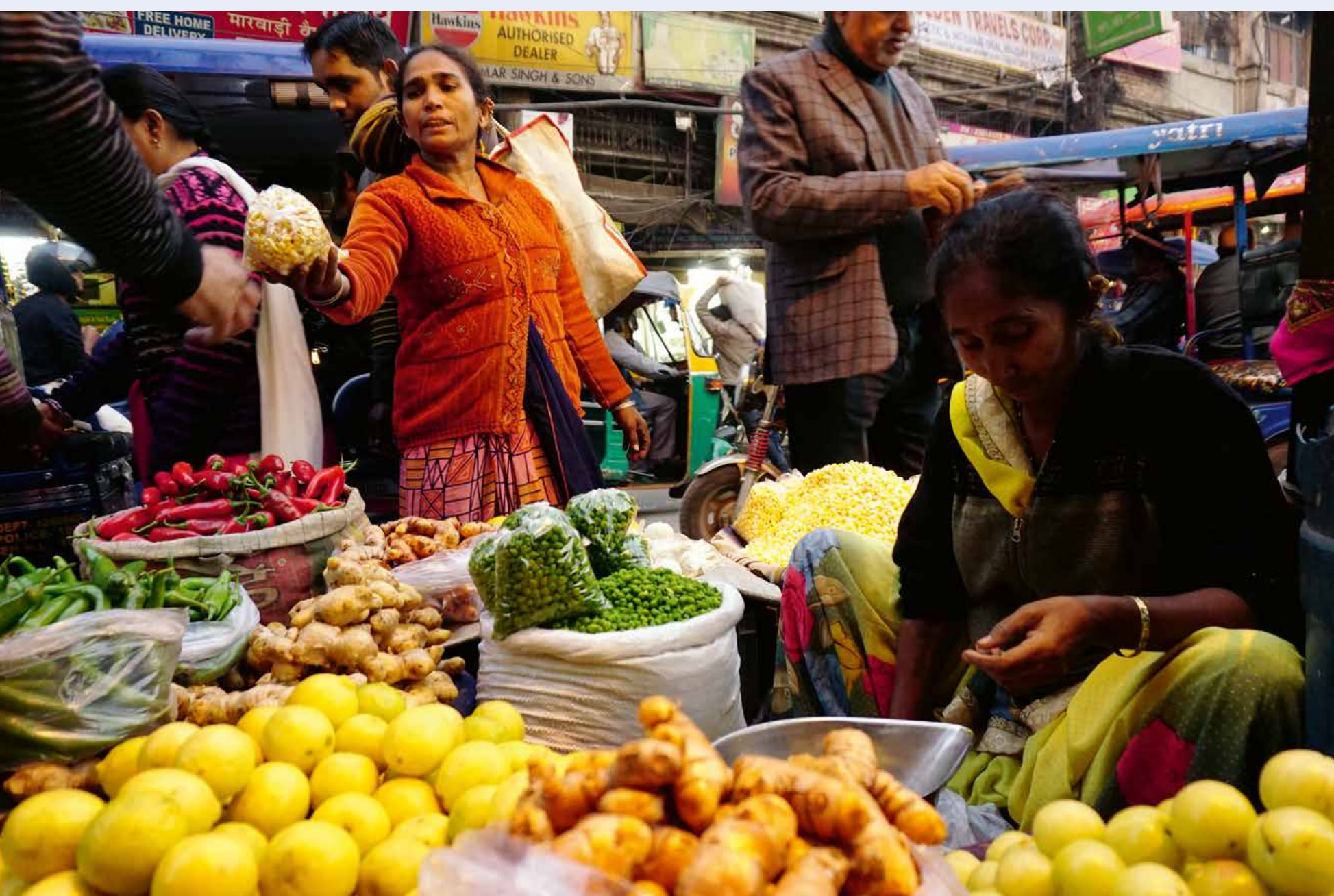


is co-hosting, provides an ideal platform for holding these discussions, as well as a vehicle to achieve the programme's capacity-building and network development activities.

Developing a domestic research programme supported by a native speaking Co-director or Associate Director, as well as post-doctoral fellows and doctoral students, could assist the initiative in at least two ways. It would provide more support to the Executive Director in his efforts to create an international programme - with students benefiting from the opening up of an enormous network of researchers (through the Scientific Committee). And it would support developing networks within China while creating a domestic research programme focused on urban health and well-being through the lens of system science.

The role and functions of the Scientific Committee should be revisited. It is clear that some functions have not been fulfilled in accordance with its initial terms of reference. The Scientific Committee, together with the Executive Director, should re-examine its own functioning and terms of reference, and aid the Executive Director in setting a new strategic and science action plan that is relevant, feasible and attainable within the remaining lifespan of the programme. The Scientific Committee should review the programme's progress against key performance indicators on a regular basis.

\section{REVIEW CRITERIA 3 SECRETARIAT, FUNDING AND OPERATIONS}

The review panel acknowledges that a lot of funding, resources, and goodwill has gone into the design, development and administration of the UHWB programme as it currently stands. It is a credit to the individuals involved, and the review panel notes the generous funding and inkind support provided thus far by the host institute and for the next phase of the programme.

The programme operates under the infrastructure of the host institution - the IUE of the CAs - which provides internal services and financial support, operating under the institution's and host country's internal standard operating procedures. However, despite the willingness to accommodate an international programme such as this one, a few practical problems preclude full implementation of the programme in China.

For example, staffing of the IPo has been a serious issue and a key gap. The programme has struggled to recruit a Science Officer (the post has been vacant for 18 months at the time of writing) and a Communications Officer - a position that had been identified as crucial for the programme's success but has remained unfilled from the start of the programme. Several rounds of interviews have been conducted only for chosen candidates to turn down the offer citing better prospects elsewhere.

The Science Officer role, as advertised, states a $\mathrm{PhD}$ is required and that $50 \%$ of the time will be dedicated to research. This is a possible reason that candidates decline: the post does not offer adequate opportunity for $\mathrm{PhD}$-level candidates to advance their research. Consideration should be given to employing master's level staff (with several years of experience) and further redrafting the position description.

The review panel recognises the challenges of an Executive Director who is a non-native speaker working without core staff. The panel recommends that a Co-director model be trialled, with a focus on the development of a domestic research programme connected to the IPO (providing a point of contact and supervision of locally recruited researchers). The Co-director role could also help supplement the current Executive Director's role, taking care to avoid duplication of responsibilities.

In making this recommendation, the review panel is cognisant of the challenge of ensuring the IPO has adequate access to financial and human resources in a rapidly changing funding environment for international scientific collaboration. Establishing an active programme of domestic research within the IUE offers opportunities, in principle, to build a critical mass, meet local institutional needs, and complement the international goals of the Uнwв programme. The IUE is, for example, best placed to attract international researchers to collaborate with the UHwB Programme and to pursue funding for discrete 
research projects. Such a model also overcomes the programme's isolation from its local context and fosters more engagement with other researchers and colleagues at the IUE.

In all, an operational mechanism to make the programme successful needs to be based on a new model of getting more students and researchers into the institute. This would embed the programme within the IUE and enable it to benefit from research undertaken there. This model would also go a long way in ensuring the sustainability of the programme beyond its current lifespan.

\section{REVIEW CRITERIA 4 STAKEHOLDERS AND PARTNERSHIPS}

The uнwв programme has cultivated and engaged with a large network of stakeholders and partners - through the various events, workshops, and conferences undertaken or attended. However, strategic long-term partnerships have yet to be formalized.

The programme has begun to develop working relationships with a variety of other ICSU programmes and bodies. For example, the Executive Director plays a role in three of Future Earth's Knowledge Action Networks (Health, Urban, and Risk). All Future Earth Knowledge Action Networks are in various stages of development, which the programme has been able to influence. The programme has also recently started to engage and work with ICsu's regional offices, developing plans for different regional perspectives on an urban health model that will be policy-facing. Again, there is a lack of formal partnership in the way the programme operates, meaning that concrete outputs and activities have yet to materialize.

The programme's current sponsors (UNU-IIGH, ICSU, and IAP) all engage well with the programme, and provide much intellectual support. ICSU works to place the programme in highlevel United Nations policy spheres (such as the Habitat III conference in Quito), and UNU-IIGH at the World Urban Forum in Kuala Lumpur.
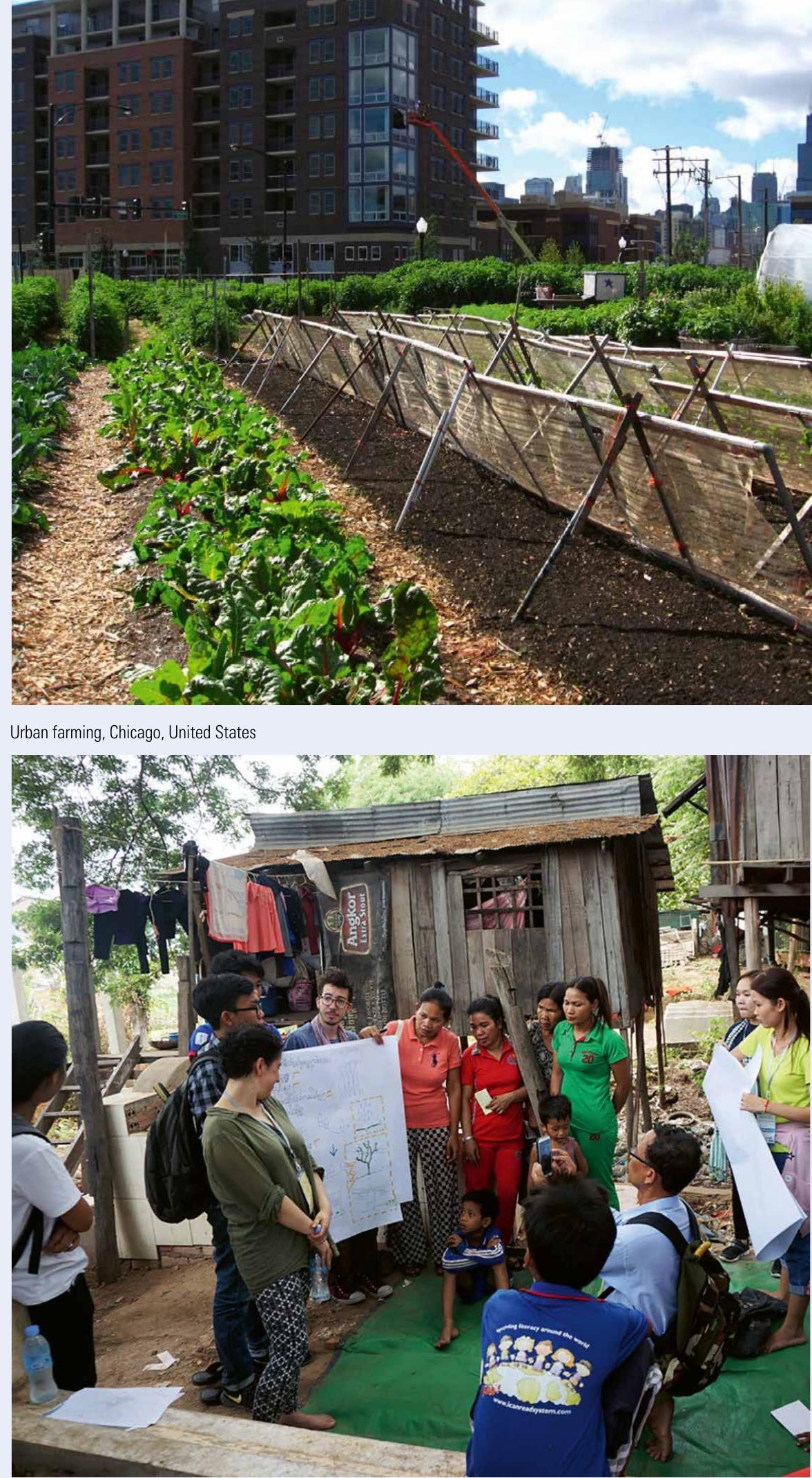

Urban Design workshop with students and community members, Phnom Penh, Cambodia

However, support from co-sponsors is not prevalent at senior levels of the organization, and it is hard to get a sense of the strategic importance of the programme for the sponsoring organizations.

Recently though, IAP has started to use the programme as a way to show its membership 
(which is mainly medical/science based) of the far-reaching importance of the link between health and the urban environment. As a result, the IPO Executive Director has been invited to present the programme at the IAP General Assembly. This has led to IAP placing more importance and emphasis on its other activities that link health to sustainable development (such as its One Health activities).

The UNU-IIGH has recently undergone a strategic review; therefore, how the programme aligns with UNU-IIGH's new strategic direction is yet to be seen. The programme is in close contact with the new leadership at the time of writing.

Also at the time of writing, ICSU is undergoing a merger with the International Social Science Council (ISsC), and the future of its scientific activities is yet to be defined. However, bringing in the ISSC and having social science on board fits well with the objectives of the Uнwв programme, so it is likely the merger will strengthen its scientific foundation. The programme has yet to define working relationships with the key international organizations in this space - such as the World Health Organization and the Wellcome Trust - but future strategic discussions will focus more on how these big players are operating.

As part of the strategic planning exercise that defines the mission and vision of the programme and what could be achieved within existing resources, efforts should be made to identify strategic partners with whom the programme should work. This should include clear objectives relating to desirable outcomes sought from the partnership. Such objectives would assist in prioritizing efforts and provide a filter through which to review upcoming opportunities. Potential partners could include those in the policy (international and domestic in China) as well as academic spheres. It is critical that partnerships include those regional offices of ICSU which have urban health as a priority. This would enable the programme to work in priority global regions, providing synergies and amplification of the programme's impact. A starting point will be working with those regional offices located in rapidly growing regions as noted above.

\section{REVIEW CRITERIA 5 COMMUNICATION, VISIBILITY

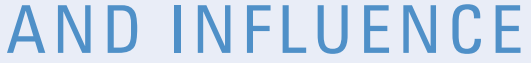

Currently, despite the broad network of actors with which it has engaged, the Uнwв programme has struggled to show influence in what it does. Communication has proved problematic, mainly due to the fact that the secretariat role has gone unfilled since the beginning of the programme. Currently, an intern aids the Executive Director with updating the programme's web pages. However, this is a short-term strategy, and hiring a Communications Officer would allow the programme to operate in a much more strategic mode.

The programme is isolated from its local context so visibility in China needs to be enhanced. It is necessary for the Executive Director and officers to interact with local and Chinese domestic government officials and scientists. It is also necessary to translate the programme's key publications (in Chinese and English) as a way to increase impact and make communication more accessible.

These efforts, together with a clear strategic direction, will allow the programme to be much more targeted in the way it operates and in its use of resources.

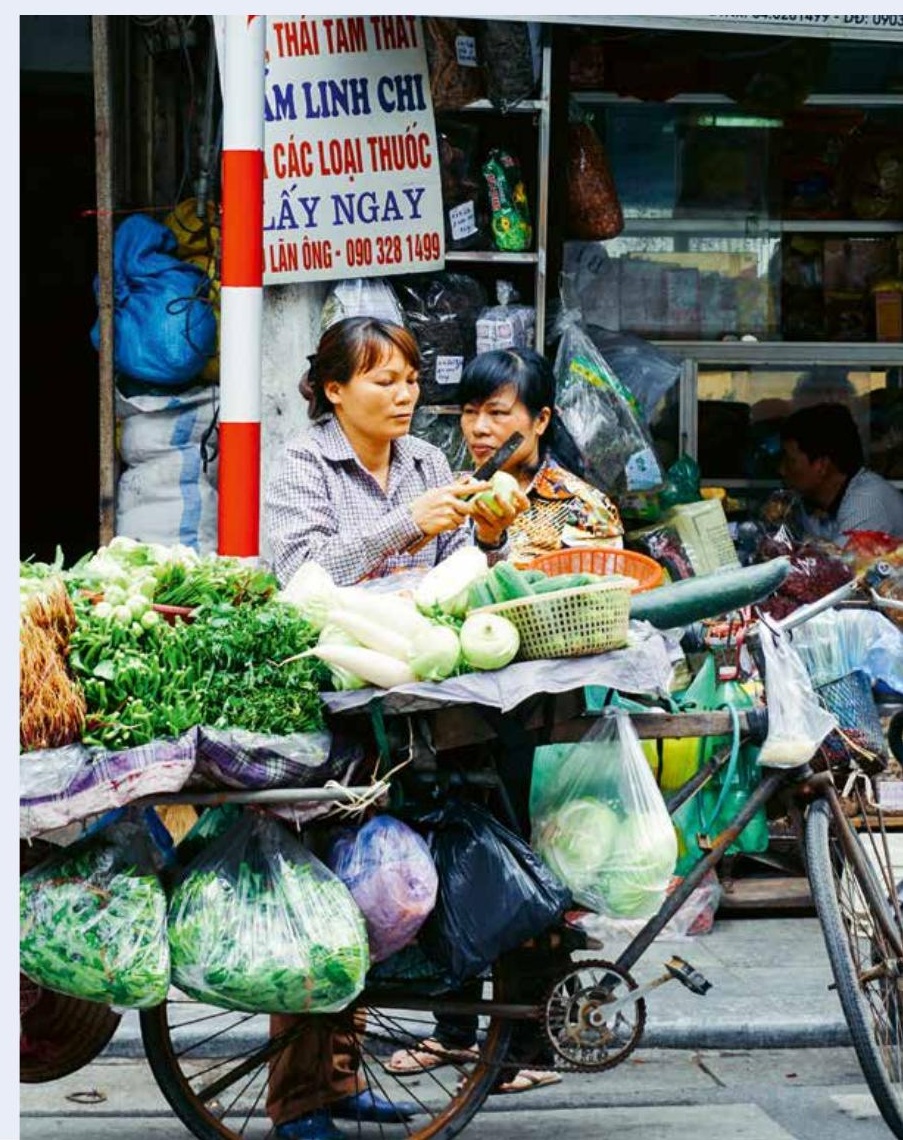


. 10

- $5 \sin$.

arnos

Led

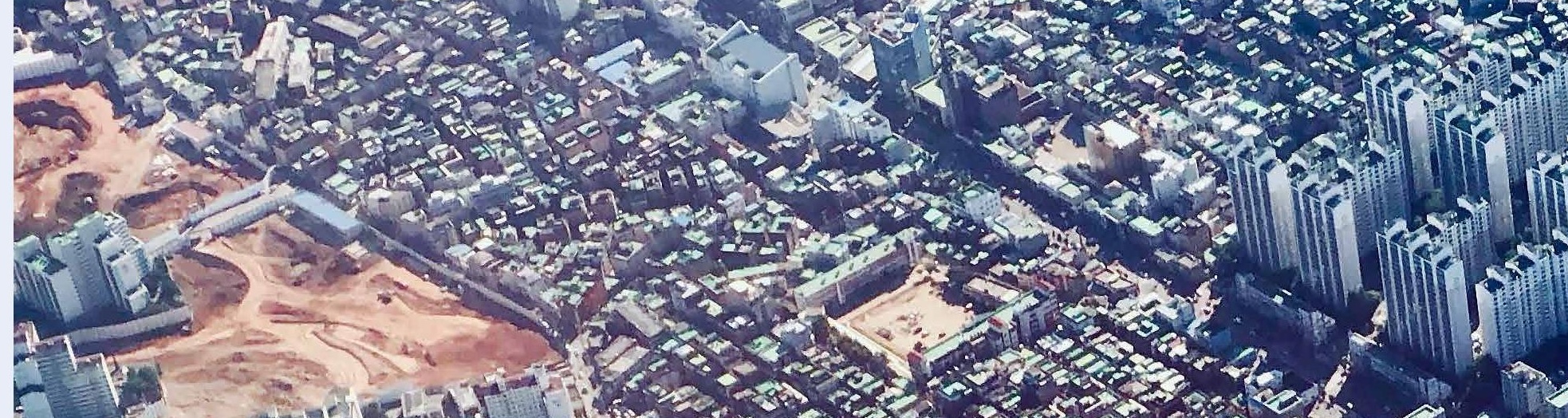

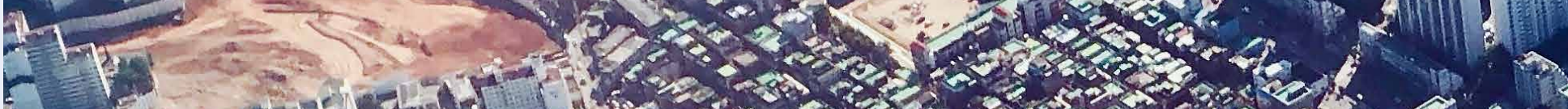

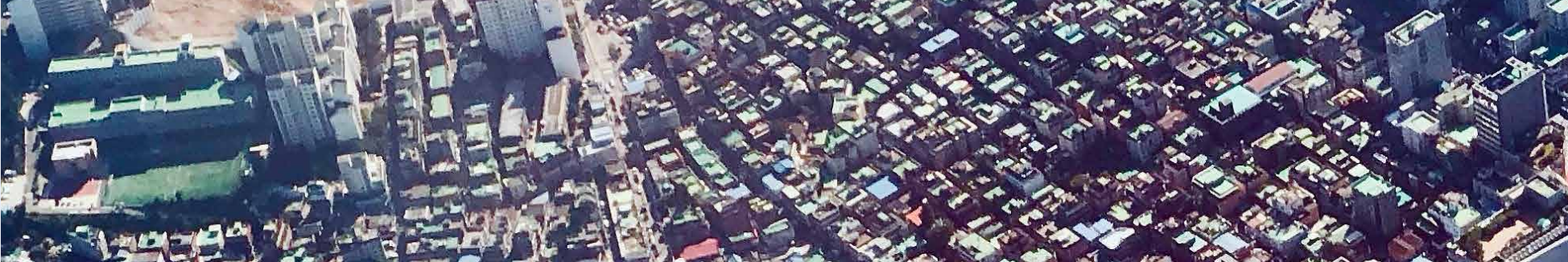
Syly

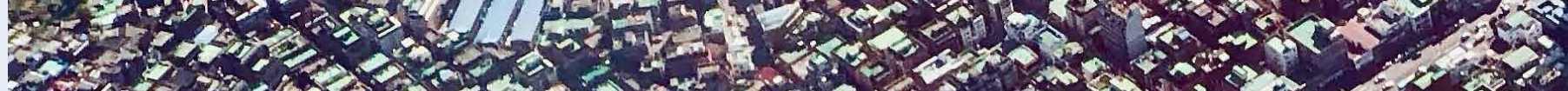
(25. )

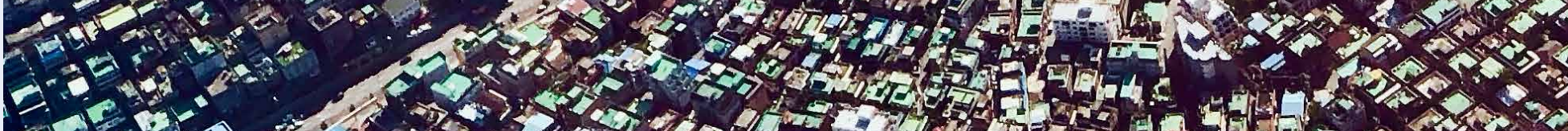

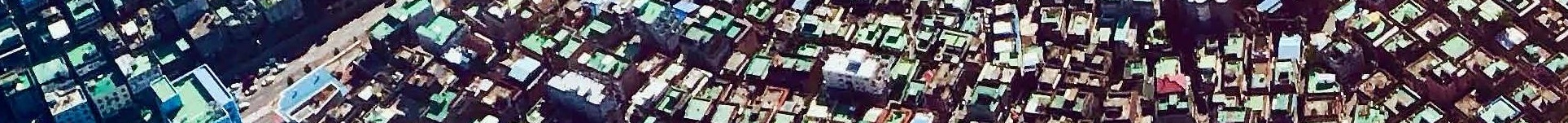

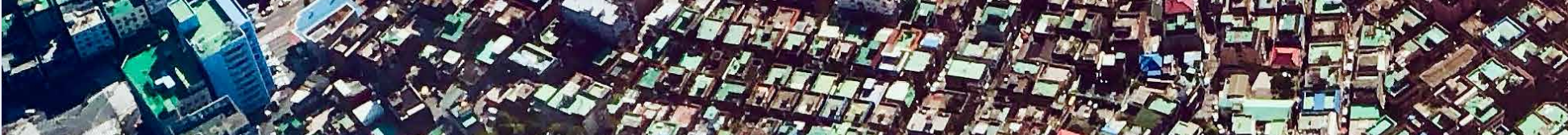

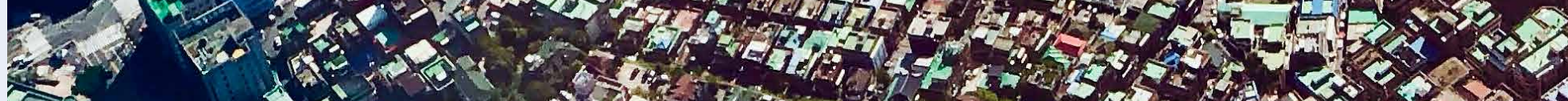
$762 y^{2}$ 1) bo - 0.5 - . .

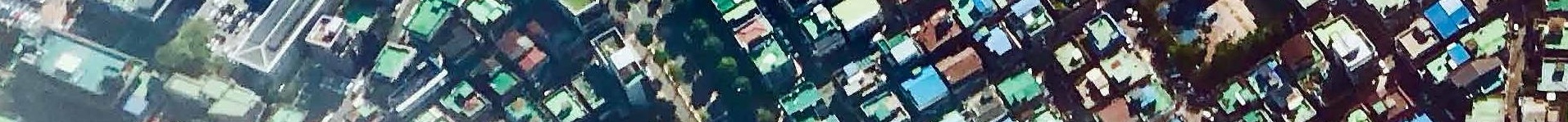

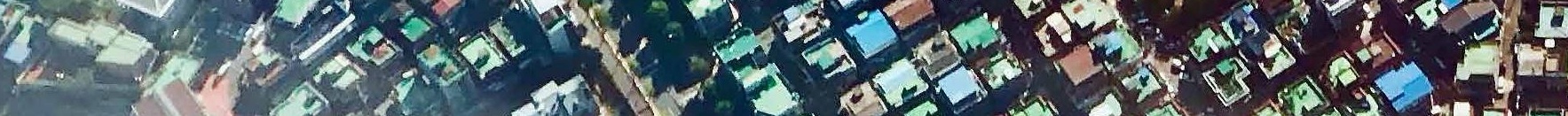

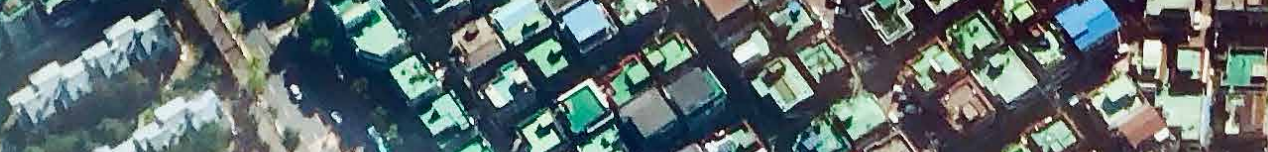




\section{FUTURE DEVELOPMENT}

\section{ROLE OF THE SCIENTIFIC COMMITTEE}

As stated above, the review panel strongly encourages the Scientific Committee to:

- Review its own terms of reference and activities as they pertain to the IPO.

- Oversee a revision of the science plan.

- Develop and monitor implementation of a strategic plan which prioritizes activities and includes key performance indicators.

In so doing, little value is added in focussing on countries/regions where integrated research is already strong. Rather, the main gaps in research and capability lie in rapidly urbanizing parts of Asia, Africa and South America. Given that the regional offices have shown considerable interest in collaborating with UHWB, the IPO and the Scientific Committee should build on this and endeavour to strengthen these partnerships.

\section{STRATEG I C PLAN ING}

As stated above, the review panel strongly encourages the Scientific Committee to work with the Executive Director to revise the science plan in order to ensure goals and objectives are strategic, relevant, feasible and attainable in the time remaining in the lifetime of the UHWB programme.

In so doing, the review panel recommends that the IPO establish a strategic plan that includes a logic model and/or metrics of measurement (e.g. key performance indicators) that would serve both as a rudder for day-to-day operations as well as a framework for evaluation.

\section{RECOMMENDATIONS TO THE}

INTERNATIONAL SCIENCE COUNCIL

The review panel recommends that the Isc support a governance model that allows for appointment of a Co-director. This Co-director would be tasked with development of a domestic research programme in urban health and well-being (including development of postgraduate and post-doctoral programmes) and facilitating stronger linkages between the IPO, the IUE, and other domestic stakeholders.

The review panel also encourages the ISC as well as the Scientific Committee to support the IPO in the hiring of necessary staff.

Given the global importance of urbanization and urban health, the review panel encourages long-term support of the programme on the global stage and continued bridging of the programme and its concepts to the global policy arena. 
LIST OF ACRONYMS

CAS
IAP
ICSU
IPO
ISC
ISSC
ISUH
IUE
UHWB
UNU-IIGH

REVIEW PANEL MEMBERS

\author{
Chinese Academy of Sciences \\ InterAcademy Partnership \\ International Council for Science \\ International Programme Office \\ International Science Council \\ International Social Science Council \\ International Society for Urban Health \\ Institute of Urban Environment \\ Urban health and well-being \\ United Nations University International \\ Institute of Global Health
}

SUSAN ELLIOTT

STEWART LOCKIE

BILLIE GILES-CORTI

CARMENCITA PADILLA

CHEN WEIOIANG

\section{LIST OF INTERVIEWEES}

JOSE SIRI

PETER MCGRATH

MONTIRA PONGSIRI

EULALIE RUAN

SHARIZAD DAHLAN

MANUEL LIMONTA

YONG-GUAN ZHU

JIELING LIU

VICTOR ABASS

FRANZ GATZWEILER

PHILIPPA HOWDEN-CHAPMAN

FUMIKO KATSUGA

SUSAN PARNELL

CARLOS DORA

HEIDE HACKMANN

JO IVEY BOUFFORD

QUNLI HAN

PASCALE ALLOTEY
University of Waterloo

Committee on Scientific Planning and Review, ICSU

RMIT University

University of Philippines

Chinese Academy of Sciences
Senior Research Fellow, UNU-IIGH

Coordinator, IAP

Senior Research Associate, Cornell University

Administration Assistant, IPO

Science Officer, ICsu Regional Office for Asia-Pacific

Director, ICsu Regional Office for Latin America

Director, IUE, CAS

intern and $\mathrm{PhD}$ candidate, Lisbon University

$\mathrm{PhD}$ candidate and webpage maintenance, IUE

Director, uнwв programme

Scientific Committee Chair, uнwв programme

Global Hub Director, Future Earth Japan

Professor, African Cities Institute

World Health Organization

CEO, ISC (from July 2018); Executive Director, ICSU (to July 2018)

President, New York Academy of Medicine

Executive Director, Integrated Research on Disaster Risk programme

Director, UNU-IIGH

\section{REFERENCES}

ICSU. 2011. Health and Wellbeing in the Changing Urban Environment: a Systems Analysis Approach. An Interdisciplinary Science Plan: Report of an Icsu Planning Group. Paris, Icsu.

https://council.science/cms/2017/05/Health-and-wellbeing-in-the-changing-urban-environment-web.pdf 


\section{IMPRINT}

INTERNATIONAL SCIENCE COUNCIL

5 , rue Auguste Vacquerie

75116 Paris, France

Tel. +33 (0)1 45250329

Fax +33 (0)1 42889431

secretariat@council.science

www.council.science

\section{PHOTO CREDITS}

Cover: Ckturistando on Unsplash

P. 02: Holger Link on Unsplash

P. 04: Lim Eng on Unsplash

P. 06: Olga Frolova on Unsplash

P. 07: Paul Krueger on Flickr

P. 08: Fikri Rasyid on Unsplash

P. 09: Stephanie Liao on Unsplash

P. 11: Johnny Miller on Flickr

P. 12: Linda N. on Flickr

P. 12: Development Planning Unit University College London on Flickr

P. 13: Jack Young on Unsplash

P. 14: Clark Gu on Unsplash

\section{DESIGN}

Public Design Hamburg - www.pblcdsgn.de

DOI: $10.24948 / 2019.01$ 


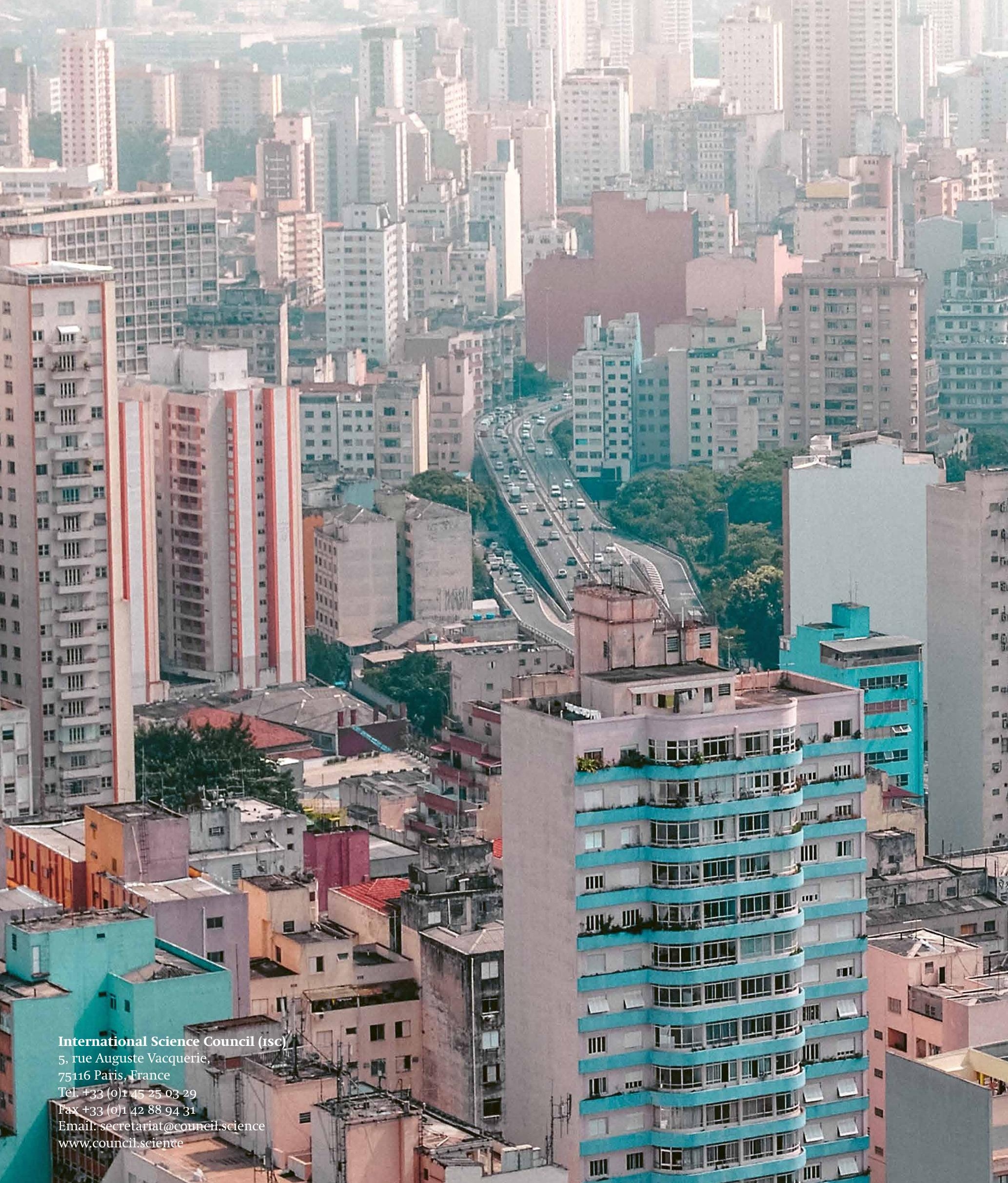

